\title{
Analisis Kualitas Air dan Status Mutu Air Sungai Batang Asam Akibat Limbah Cair Kelapa Sawit Menggunakan Metode Indeks Pencemaran
}

\author{
Siti Umi Kalsum*, Lailal Gusri, Junardi \\ Program Studi Teknik Lingkungan Universitas Batanghari \\ *e-mail: siti.uk0616@gmail.com
}

\begin{abstract}
ABSTRAK
Sungai Batang Asam sebagai sumber air baku Sistim Penyediaan Air Minun (SPAM) dan kebutuhan sehari-hari. Pada tanggal 19 Mei 2015 telah terjadi pencemaran di Sungai Batang Asam akibat dari tumpahnya limbah cair kelapa sawit dari salah satu perusahaan sawit di sekitar Sungai Batang Asam. Air sungai menjadi berbau dan berwarna hitam serta ikan banyaknya yang mati. Pengujian awal menunjukkan bahwa parameter BOD =10 mg/l, COD = $50 \mathrm{mg} / \mathrm{l}, \mathrm{TSS}=16 \mathrm{mg} / \mathrm{l}, \mathrm{N}$ Total $=3,86 \mathrm{mg} / \mathrm{l}, \mathrm{pH}=6,02$, Minyak dan lemak $=2,8 \mathrm{mg} / \mathrm{l}$ dimana hampir semua parameter melebihi baku mutu. Penelitan ini bertujuan untuk menganalisis kualitas air dan status mutu air Sungai Batang Asam akibat limbah cair kelapa sawit menggunakan metode Indeks Pencemaran. Pengambilan sampel air Sungai Batang Asam dilakukan pada 4 (empat) lokasi yaitu daerah Hulu Desa Lubuk Bernai, daerah Tengah Desa Lubuk Lawas dan Desa Tanjung Bojo dan daerah Hilir Desa Kampung Baru (Muara Sungai Pengabuan). Parameter yang diuji adalah pH, TSS, TDS, BOD,COD, DO, Fe, Minyak dan lemak yang berdasarkan pada Peraturan Pemerintah Nomor 82 Tahun 2001 tentang Pengelolaan Kualitas Air dan Pengendalian Pencemaran Air Kelas II (dua). Analisis Status Mutu air menggunakan metode Indeks Pencemaran yang dilakukan berpedoman pada Permen LH Nomor 115 Tahun 2003 Tentang Pedoman Penentuan Status Mutu Air. Hasil penelitian menunjukkan bahwa analisis kualitas air Sungai Batang Asam rata-rata dari 4 (empat) lokasi yang diuji adalah parameter $\mathrm{pH} \quad 6,8$, parameter TDS 79,5 mg/l, parameter TSS 15,25 mg/l, parameter DO 3,025 mg/l, parameter BOD 2,935 $\mathrm{mg} / \mathrm{l}$, parameter COD 14,5 mg/l, Fe 0,645 mg/l dan parameter minyak dan lemak $1 \mathrm{mg} / \mathrm{l} \mathrm{masih} \mathrm{memenuhi} \mathrm{baku} \mathrm{mutu} \mathrm{kualitas} \mathrm{air} \mathrm{kelas}$ II (PP No. 82 Tahun 2001). Sedangkan status mutu air Sungai Batang Asam akibat limbah cair kelapa sawit menunjukkan bahwa status mutu air kategori tercemar ringan dengan nilai indeks pencemaran $1,0 \leq \mathrm{IP} \leq 5,0$ yaitu 1,96.
\end{abstract}

Kata kunci : Kualitas air; Metode IP; Status mutu air; Sungai Batang Asam.

\begin{abstract}
Batang Asam River as a source of raw water for Drinking Water Supply Systems (SPAM) and daily needs. On May 19, 2015 there was pollution in the Batang Asam River due to the spillage of palm oil wastewater from one of the palm oil companies around the Batang Asam River. The water river becomes smelly and black and many fish die. The initial testing showed that BOD parameter $=$ $10 \mathrm{mg} / 1), \mathrm{COD}=50 \mathrm{mg} / 1, \mathrm{TSS}=16 \mathrm{mg} / 1, \mathrm{~N}-\mathrm{Total}=3.86 \mathrm{mg} / 1, \mathrm{pH}=6.02$, Oil and fat $=2.8 \mathrm{mg} / 1$, where almost all parameters above the quality standard. The purpose of this study was to analyze status of water and water quality of Batang Asam River Using Pollution Index Method as a result of spilling palm oil wastewater. Water sampling of the Batang Asam River was carried out in 4 (four) locations, namely the upstream area of Lubuk Bernai Village, the Central area of Lubuk Lawas Village and Tanjung Bojo Village and the downstream of Kampung Baru Village (Pengabuan River Estuary). Parameters tested were pH, TSS, TDS, BOD, COD, DO, Fe, Oil and fat based on Government Regulation Number 82 of 2001 concerning Water Pollution Control and Water Quality Management For Class II. Analysis of water quality status using the Pollution Index method based on the Minister of Environment Regulation Number 115 of 2003 concerning Guidelines for Determining the Status of Water Quality. The results showed that the analysis of the average waterquality of Batang Asam River from four locations tested were parameters $\mathrm{pH} 6,8$, TDS parameters 79,5 mg / 1, TSS parameters 15,25 mg / 1, DO parameters 3,025 mg / 1, BOD parameters 2,935 mg/l, COD parameters 14,5 $\mathrm{mg} / 1, \mathrm{Fe} 0,645 \mathrm{mg} / 1$ and parameters of oil and fat $1 \mathrm{mg} / 1$ satisfy the class II water quality standard (PP No. 82 of 2001). The status of Batang Asam River shows that the status of water quality is mildly polluted with a pollution index value of $1,0 \leq \operatorname{IP} \leq 5,0$ which is 1,96 .
\end{abstract}

Keywords: Batang Asam River; Pollution Index Method; Status of water quality; Water quality.

\section{Pendahuluan}

Sungai merupakan alur atau wadah air alami danataubuatan berupa jaringan pengaliran air beserta air didalamnya, mulai dari hulu sampai muara, dengandibatasi kanan dan kiri oleh garis sempadan (Peraturan PemerintahNo. 38 Tahun
2011). Sungai adalah salah satu sumber daya alam yang bersifat mengalir sehingga pemanfaatan air di hulu akan menghilangkan peluang di hilir. Pencemaran sungai di hulu akan menimbulkan biaya sosial di hilir dan pelestarian di hulu memberikan manfaat di hilir. Sungai sangat bermanfaat bagi manusia dan biota air (Candra, 
2005).Perubahan tata guna lahan dari hutan menjadi pemukiman dan industri dan meningkatnya aktivitas penduduk, pertanian dan industri akan berpengaruh pada kualitas air sungai (Priyambada, et, al, 2008). Kualitas air sungai merupakan kondisi kualitatif yang diukur berdasarkan parameter tertentu dan dengan metode tertentu sesuai peraturan perundangan yang berlaku. Kualitas air sungai dapat dinyatakan dengan parameter yang menggambarkan kualitas air tersebut. Parameter tersebut meliputi parameter fisika, kimia dan biologi. Parameter-parameter kualitas air sungai dapat berubah berdasarkan kondisi alami maupun adanya aktivitas antropogenik. Aktivitas antropogenik yang mempengaruhi kualitas air sungai berasal dari perubahan pola pemanfaatan lahan, kegiatan pertanian, permukiman serta industri. Kegiatan pertanian dan permukiman pada dasarnya merubah bentang alam melalui pengolahan tanah, sehingga akan mempengaruhi kualitas air sungai (Asdak, 2010).Indikator bahwa air telah tercemar adanya perubahan atau tanda yang dapat diamati melalui: 1. adanya perubahan suhu air;2. adanya perubahan $\mathrm{pH}$ atau konsentrasi ion hidrogen;3. adanya perubahan warna, bau dan rasa air;4. timbulnya endapan koloidal, bahan pelarut;5. adanya mikroorganisme;6. meningkatnya radioaktivitas air lingkungan (Wardhana, 2004).Sungai Batang Asam secara administrasi berada di wilayah Kecamatan Batang Asam. Hulunya berada di Desa Lubuk Bernai dan hilir muaranya ke Sungai Pengabuan, dengan panjang sungai $\pm 12 \mathrm{~km}$. Sungai Batang Asam dimanfaatkan oleh masyarakat sebagai sumber air untuk kebutuhan sehari-hari dan air baku Sistim Penyediaan Air Minun (SPAM) Tirta Pengabuan. Pada tanggal 19 Mei 2015 terjadi pencemaranair di Sungai Batang Asam, akibat tumpahnya cairan limbah sawit dari outlet IPAL perusahaan sawit di sekitar sungai. Dampak dari tumpahan limbah sawit ini mengakibatkan ikan mati dan air berwarna hitam serta berbau. Warga pun khawatir air limbah tersebut mengancam kelanjutan dari penggunaan air sungai sebagai kebutuhan air sehari-hari. Pada pengujian awal yang dilakukan pada kualitas air Sungai Batang Asam ini menunjukkan bahwa parameter BOD (10 mg/l), COD (50 mg/l), TSS (16 $\mathrm{mg} / \mathrm{l}), \mathrm{N}$ - Total $(3,86 \mathrm{mg} / \mathrm{l}), \mathrm{pH}(6,02)$ Minyak dan lemak (2,8 mg/l). Dari hasil uji sampel hampir semua parameter melebihi baku mutu.Untuk mengetahui status dan mutu air dari sautu perairan, maka digunakan suatu pedoman penentuan status mutu air yang tertuang pada Keputusan Menteri Lingkungan Hidup Nomor 115 Tahun 2003. Tujuan penelitan ini untuk menganalisis status dan mutu air Sungai Batang Asam Menggunakan Metode Indeks Pencemaran akibat dari tumpahnya limbah cair kelapa sawit.

\section{Metode Penelitian}

\subsection{Lokasi Penelitian}

Lokasi penelitian dilakukan pada Sungai Batang Asam Kecamatan Batang Asam Kabupaten Tanjung Jabung Barat Provinsi Jambi dengan 4 (empat) lokasi mulai dari hulu sampai muara sungai. Peta lokasi penelitian disajikan pada Gambar 1.

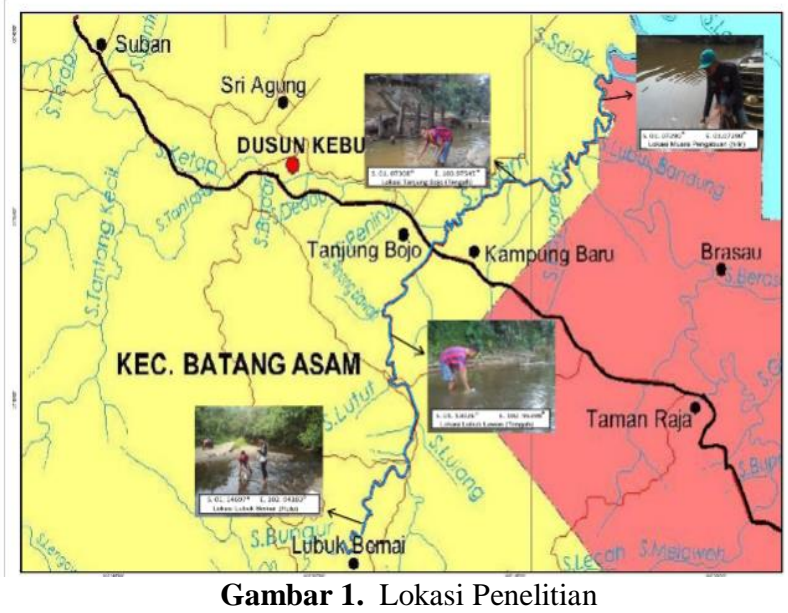

\subsection{Metode Indeks Pencemaran}

Salah satu metode dalam penentuan status mutu air yang ada di Indonesia adalah menggunakan metode indeks pencemaran sesuai yang tertuang dalam KepMen LH Nomor 115 Tahun 2003. Formula yang digunakan seperti dibawah ini

$$
I P_{j}=\sqrt{\frac{\left(C_{i} / L_{i j}\right)_{M}^{2}+\left(C_{i} / L_{i j}\right)_{R}^{2}}{2}}
$$

dengan $I P_{j}$ adalah indeks pencemaran bagi peruntukan $j, \mathrm{C}_{i}$ adalah konsentrasi parameter kualitas air $\mathrm{i}, \mathrm{L}_{\mathrm{ij}}$ adalah konsentrasi parameter kualitas air i yang tercantum dalam baku peruntukan air $\mathrm{j}$, sementara $\mathrm{M}$; maksimum, R; rerata. Indeks kualitas air IP untuk target multifungsi air ditentukan dari resultante nilai maksimum dan nilai rerata rasio konsentrasi per parameter terhadap nilai baku mutunya dengan keterangan berikut.

a. Jika nilai konsentrasi parameter menurun menyatakan tingkat pencemaran meningkat;

$$
\left(C_{i} / L_{i j}\right)_{b a r u}=\frac{\left.C_{i m}-C_{i} \text { (hasil pengukuran }\right)}{C_{i m}-L_{i j}}
$$

b. Jika nilai $\left(\mathrm{C}_{\mathrm{i}} / \mathrm{L}_{\mathrm{ij}}\right)$ hasil pengukuran lebih besar dari 1 , maka:

$$
\left(C_{i} / L_{i j}\right)_{\text {baru }}=1,0+P \cdot \log \left(C_{i} / L_{i j}\right)_{\text {hasil pengukuran }}
$$

c. Jika nilai baku $\mathrm{L}_{\mathrm{ij}}$ memiliki rentang

$\mathrm{C}_{\mathrm{i}}<\mathrm{L}_{\mathrm{ij}}$ rata-rata, maka

$$
\left(C_{i} / L_{i j}\right)_{\text {baru }}=\frac{\left[C_{i}-\left(L_{i j}\right)_{\text {rata-rata }}\right]}{\left\{\left(L_{i j}\right)_{\text {minimum }}-\left(L_{i j}\right)_{\text {rata-rata }}\right\}}
$$

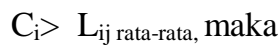

$$
\left(C_{i} / L_{i j}\right)_{\text {baru }}=\frac{\left[C_{i}-\left(L_{i j}\right)_{\text {rata-rata }}\right]}{\left\{\left(L_{i j}\right)_{\text {minimum }}-\left(L_{i j}\right)_{\text {rata-rata }}\right\}}
$$


Metode IP jika untuk beberapa peruntukan air cara pembobotan berbeda-beda, yaitu dengan rumus:

$I P=\sum_{j=1}^{j=n} w_{j} I P_{j}$ dan $\sum_{j=1}^{j=n} w_{j}=1$

tercemar sedang (fairly polluted) dan IP > 10 tercemar berat.

\section{Hasil dan Pembahasan}

\subsection{Hasil Penelitian}

Pengambilan sampel airSungai Batang Asam dilakukan di 4 (empat) lokasi antara laintitik 1 Desa Lubuk Bernai (hulu) koordinat S: $01.14697{ }^{\circ} \mathrm{E}: 102$.
Pencemaran (Kalsum,S.I, Gusri, L., Junardi) dengan wij adalah bobot masing-masing jenis penggunaan air. Kelas indeks IP memiliki skor antara lain; $0 \leq \mathrm{IP} \leq 1,0$, memenuhi baku mutu $($ good $) ; 1,0<\mathrm{IP}$ $\leq 5,0$; tercemar ringan (slightly polluted); 5,0 < IP $\leq 10$; 94183, titik 2 Desa Lubuk Lawas (tengah 1) $\mathrm{S} ; 01.13026^{\circ} \mathrm{E}: 102.96398^{\circ}$, titik 3 Desa Tanjung Bojo (tengah 2) S: $01.07308^{\circ} \mathrm{E}: 103.97545^{\circ}$ dan titik 4 Desa Kampung Baru (Muara Sungai)S:01.07290 E: $\left.104.07290^{\circ}\right)$.Hasil uji kualitas air disajikan pada Tabel 1 dan Tabel 2. Sedangkan hasil analisis status mutu air menggunakan metode indeks pencemaran disajikan pada Tabel 3 sampai Tabel 6.

Tabel 1. Hasil Uji Kualitas Air Sungai Batang Asam (Pagi)

\begin{tabular}{ccccccc}
\hline No & Parameter & Satuan & Titik1 & Titik2 & Titik3 & Titik4 \\
\hline 1 & $\mathrm{pH}$ & - & 6,80 & 6,90 & 6,85 & 6,71 \\
2 & $\mathrm{TSS}$ & $\mathrm{mg} / \mathrm{L}$ & 6 & 12 & 14 & 16 \\
3 & $\mathrm{TDS}$ & $\mathrm{mg} / \mathrm{L}$ & 90 & 74 & 64 & 96 \\
4 & $\mathrm{DO}$ & $\mathrm{mg} / \mathrm{L}$ & 4,0 & 3,83 & 2,90 & 2,42 \\
5 & $\mathrm{BOD}$ & $\mathrm{mg} / \mathrm{L}$ & 2,01 & 4,82 & 2,82 & 2,81 \\
6 & $\mathrm{COD}$ & $\mathrm{mg} / \mathrm{L}$ & 14 & 14 & 18 & 16 \\
7 & Besi & $\mathrm{mg} / \mathrm{L}$ & 0,58 & 0,47 & 0,75 & 0,63 \\
8 & M \& L & $\mathrm{mg} / \mathrm{L}$ & $<2$ & 3,2 & $<2$ & $<2$ \\
\hline \multicolumn{7}{l}{ Sumber: Analisis, 2015} \\
\end{tabular}

Tabel 2. Hasil Uji Kualitas Air Sungai Batang Asam (sore)

\begin{tabular}{ccccccc}
\hline No & Parameter & Satuan & Titik1 & Titik2 & Titik3 & Titik4 \\
\hline 1 & $\mathrm{pH}$ & - & 6,83 & 6,79 & 6,79 & 6,69 \\
2 & $\mathrm{TSS}$ & $\mathrm{mg} / \mathrm{L}$ & 18 & 24 & 14 & 18 \\
3 & $\mathrm{TDS}$ & $\mathrm{mg} / \mathrm{L}$ & 72 & 82 & 62 & 96 \\
4 & $\mathrm{DO}$ & $\mathrm{mg} / \mathrm{L}$ & 4,0 & 3,75 & 2,43 & 2,13 \\
5 & $\mathrm{BOD}$ & $\mathrm{mg} / \mathrm{L}$ & 3,22 & 2,82 & 2,41 & 2,41 \\
6 & $\mathrm{COD}$ & $\mathrm{mg} / \mathrm{L}$ & 16 & 18 & 9 & 11 \\
7 & $\mathrm{Besi}$ & $\mathrm{mg} / \mathrm{L}$ & 0,38 & 0,61 & 0,82 & 0,98 \\
8 & $\mathrm{M} \& \mathrm{~L}$ & $\mathrm{mg} / \mathrm{L}$ & $<2$ & $<2$ & $<2$ & $<2$ \\
\hline \multicolumn{5}{l}{ Sumber: Analisis, 2015}
\end{tabular}

Tabel 3. Hasil Analisis Metode Indeks Pencemaran (Hulu)

\begin{tabular}{|c|c|c|c|c|c|c|c|c|c|}
\hline \multirow[t]{2}{*}{ No } & \multirow[t]{2}{*}{ Parameter } & \multicolumn{2}{|c|}{$\mathrm{C}_{\mathrm{i}}$} & \multicolumn{2}{|c|}{$\mathrm{L}_{\mathrm{ij}}$} & \multicolumn{2}{|c|}{$\mathrm{C}_{\mathrm{i} / \mathrm{L}_{\mathrm{ij}}}$} & \multicolumn{2}{|c|}{$\mathrm{C}_{\mathrm{i}} / \mathrm{L}_{\mathrm{ij}}$ baru } \\
\hline & & $\mathrm{P}$ & $S$ & $\mathrm{P}$ & $\mathrm{S}$ & $\mathrm{P}$ & $\mathrm{S}$ & $\mathrm{P}$ & $\mathrm{S}$ \\
\hline 1 & $\mathrm{pH}$ & 6,8 & 6,83 & 9 & 9 & 0,76 & 0,76 & 0,76 & 0,76 \\
\hline 2 & TSS & 6 & 18 & 50 & 50 & 0,12 & 0,36 & 0,12 & 0,36 \\
\hline 3 & TDS & 90 & 72 & 1000 & 1000 & 0,09 & 0,07 & 0,09 & 0,07 \\
\hline 4 & DO & 3,97 & 3,97 & 4 & 4 & 0,99 & 0,99 & 0,99 & 0,99 \\
\hline 5 & BOD & 2,01 & 3,22 & 3 & 3 & 0,67 & 1,07 & 0,67 & 1,07 \\
\hline 6 & COD & 14 & 16 & 25 & 25 & 0,56 & 0,64 & 0,56 & 0,64 \\
\hline \multirow[t]{4}{*}{8} & M \& L & $<2$ & $<2$ & 1 & 1 & - & - & - & - \\
\hline & \multicolumn{5}{|c|}{$\left(\mathrm{C}_{\mathrm{i}} / \mathrm{L}_{\mathrm{ij}}\right)_{\mathrm{R}}$} & & & 0,64 & 0,62 \\
\hline & \multirow{2}{*}{\multicolumn{5}{|c|}{$\underset{\left(C_{i} / L_{i j}\right)_{M}}{\text { IP }}$}} & & & 1,92 & 1,09 \\
\hline & & \multicolumn{4}{|c|}{ IP } & & & 1,43 & 0,89 \\
\hline
\end{tabular}

Sumber: Analisis, 2015

Tabel 4. Hasil Analisis Metode Indeks Pencemaran (Tengah1)

\begin{tabular}{|c|c|c|c|c|c|c|c|c|c|}
\hline \multirow[t]{2}{*}{ No } & \multirow[t]{2}{*}{ Parameter } & \multicolumn{2}{|c|}{$\mathrm{C}_{\mathrm{i}}$} & \multicolumn{2}{|c|}{$\mathrm{L}_{i j}$} & \multicolumn{2}{|c|}{$\mathrm{C}_{\mathrm{i}} / \mathrm{L}_{\mathrm{ij}}$} & \multicolumn{2}{|c|}{$\mathrm{C}_{\mathrm{i}} / \mathrm{L}_{\mathrm{ij}}$ baru } \\
\hline & & $\mathrm{P}$ & $\mathrm{S}$ & $\mathrm{P}$ & $\mathrm{S}$ & $\mathrm{P}$ & $\mathrm{S}$ & $\mathrm{P}$ & $\mathrm{S}$ \\
\hline 1 & $\mathrm{pH}$ & 6,9 & 6,79 & 9 & 9 & 0,77 & 0,75 & 0,77 & 0,75 \\
\hline 2 & TSS & 12 & 24 & 50 & 50 & 0,24 & 0,48 & 0,24 & 0,48 \\
\hline 3 & TDS & 74 & 82 & 1000 & 1000 & 0,07 & 0,08 & 0,07 & 0,08 \\
\hline 4 & DO & 3,37 & 3,65 & 4 & 4 & 0,84 & 0,91 & 0,84 & 0,91 \\
\hline 5 & BOD & 4,82 & 2,82 & 3 & 3 & 1,61 & 0,94 & 1,61 & 0,94 \\
\hline 6 & COD & 14 & 18 & 25 & 25 & 0,56 & 0,72 & 0,56 & 0,72 \\
\hline 7 & Besi & 0,47 & 0,607 & 0,3 & 0,3 & 1,57 & 2,02 & 1,57 & 2,02 \\
\hline 8 & $M \& L$ & 3,2 & $<2$ & 1 & 1 & 3,20 & - & 3,20 & - \\
\hline \multicolumn{8}{|c|}{$\left(\mathrm{C}_{\mathrm{i}} / \mathrm{L}_{\mathrm{ij}}\right) \mathrm{R}$} & 1,11 & 0,74 \\
\hline \multicolumn{8}{|c|}{$\left(C_{i} / L_{i j}\right) M$} & 3,2 & 2,02 \\
\hline \multicolumn{8}{|c|}{ IP } & 2,395 & 1,52 \\
\hline
\end{tabular}


Tabel 5. Hasil Analisis Metode Indeks Pencemaran (Tengah 2)

\begin{tabular}{|c|c|c|c|c|c|c|c|c|c|}
\hline \multirow[t]{2}{*}{ No } & \multirow[t]{2}{*}{ Parameter } & \multicolumn{2}{|c|}{$\mathrm{C}_{\mathrm{i}}$} & \multicolumn{2}{|c|}{ Lij } & \multicolumn{2}{|c|}{$\mathrm{Ci} / \mathrm{Lij}$} & \multicolumn{2}{|c|}{$\mathrm{Ci} / \mathrm{Lij}$ baru } \\
\hline & & $\mathrm{P}$ & $\mathrm{S}$ & $\mathrm{P}$ & $\mathrm{S}$ & $\mathrm{P}$ & $\mathrm{S}$ & $\mathrm{P}$ & $\mathrm{S}$ \\
\hline 1 & $\mathrm{pH}$ & 6,85 & 6,79 & 9 & 9 & 0,76 & 0,75 & 0,76 & 0,75 \\
\hline 2 & TSS & 14 & 14 & 50 & 50 & 0,28 & 0,28 & 0,28 & 0,28 \\
\hline 3 & TDS & 64 & 62 & 1000 & 1000 & 0,06 & 0,06 & 0,06 & 0,06 \\
\hline 4 & DO & 3,37 & 2,33 & 4 & 4 & 0,84 & 0,58 & 0,84 & 0,58 \\
\hline 5 & BOD & 2,82 & 2,41 & 3 & 3 & 0,94 & 0,80 & 0,94 & 0,80 \\
\hline 6 & COD & 18 & 9 & 25 & 25 & 0,72 & 0,36 & 0,72 & 0,36 \\
\hline 8 & $M \& L$ & $<2$ & $<2$ & 1 & 1 & - & - & - & - \\
\hline \multicolumn{8}{|c|}{$\left(\mathrm{C}_{\mathrm{i}} / \mathrm{L}_{\mathrm{ij}}\right)_{\mathrm{R}}$} & 0,76 & 0,70 \\
\hline \multicolumn{8}{|c|}{$\left(C_{i} / L_{i j}\right)_{M}$} & 2,49 & 2,72 \\
\hline \multicolumn{8}{|c|}{ IP } & 1,84 & 1,99 \\
\hline
\end{tabular}

Sumber: Analisis, 2015

Tabel 6. Hasil Analisis Metode Indeks Pencemaran (Muara)

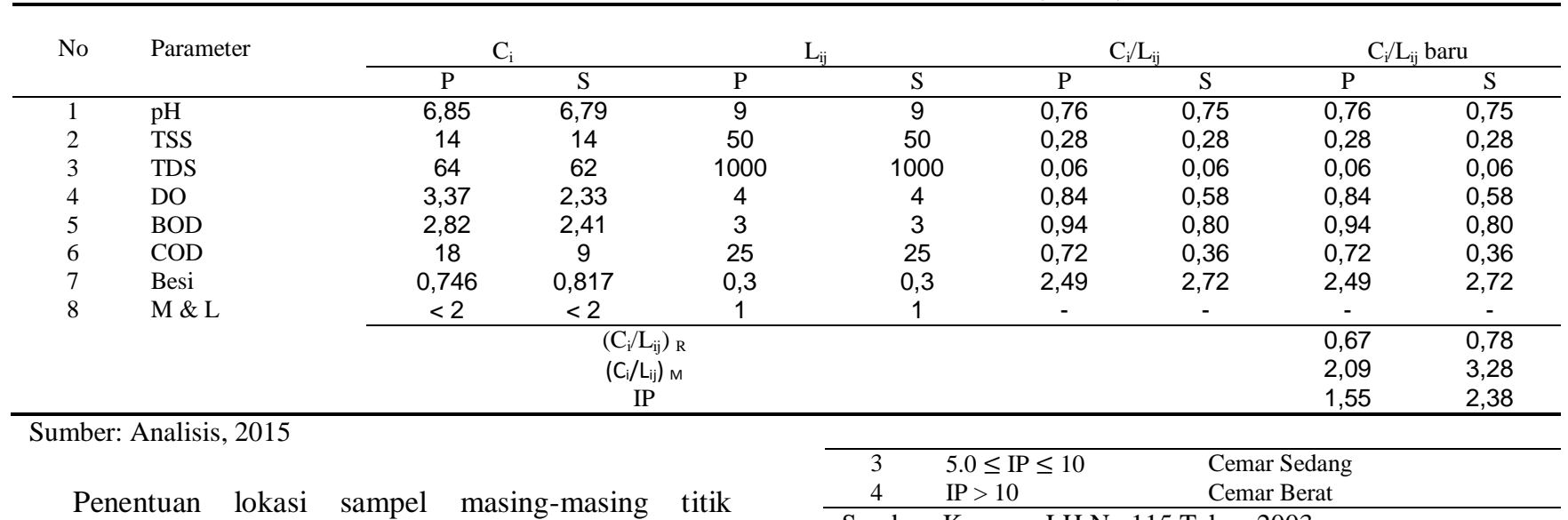
berdasarkan pada perubahan tata guna lahan dari pemukiman ke perkebunan dan industri di daerah hulu sungai dan titik-titik pertemuan aliran outlet limbah yang ada di Sungai Batang Asam. Hasil pengujian kualitas air dilakukan di Laboratorium Lingkungan Badan Lingkungan Hidup Daerah Provinsi Jambi. Sedangkan analisis perhitungan dalam penentuan status mutu air menggunakan metode indeks pencemaran dengan menggunakan persamaan (1) sampai persamaan (6). Sedangkan hasilnya tertera pada Tabel 3-6 diatas. Nilai $L_{i j}$ merupakan baku mutu air yang ditetapkan berdasarkan Peraturan Pemerintah Republik Indonesia Nomor 82 Tahun 2001 Tentang Pengendalian dan Pengelolaan Kualitas Air dan diambil kelas II sebagai air baku. Diambil Kelas II dimaksudkan karena Sungai Batang Asam dimanfaatkan sebagai air baku SPAM dan sumber air untuk kebutuhan hidup masyarakat di wilayah penelitian. Selanjutnya penentuan status mutu air menggunakan metode indeks pencemaran dapat ditentukan dari hasil nilai IP, maka dapat ditentukan status mutu air dan mengacu pada peraturan perundangan yang telah ditetapkan oleh Kepmen-LH Nomor: 115 Tahun 2003 Tentang Pedoman Penentuan Status Mutu Air pada Tabel 7 berikut.

Tabel 7. Nilai IP dan kriteria

\begin{tabular}{cll}
\hline No & \multicolumn{1}{c}{ Nilai IP } & \multicolumn{1}{c}{ Mutu Perairan } \\
\hline 1 & $0 \leq \mathrm{IP} \leq 1.0$ & Memenuhi Kriteria Mutu \\
2 & $1.0 \leq \mathrm{IP} \leq 5.0$ & Cemar Ringan \\
\hline
\end{tabular}

Sumber: Kepmen-LH No 115 Tahun 2003

Berdasarkan penentuan status mutu air menggunakan metode indeks pencemaran, maka status mutu air Sungai Batang Asam akibat limbah kelapa sawit kategori tercemar ringan dengan nilai Indeks Pencemaran $1.0 \leq \mathrm{IP} \leq 5.0$.

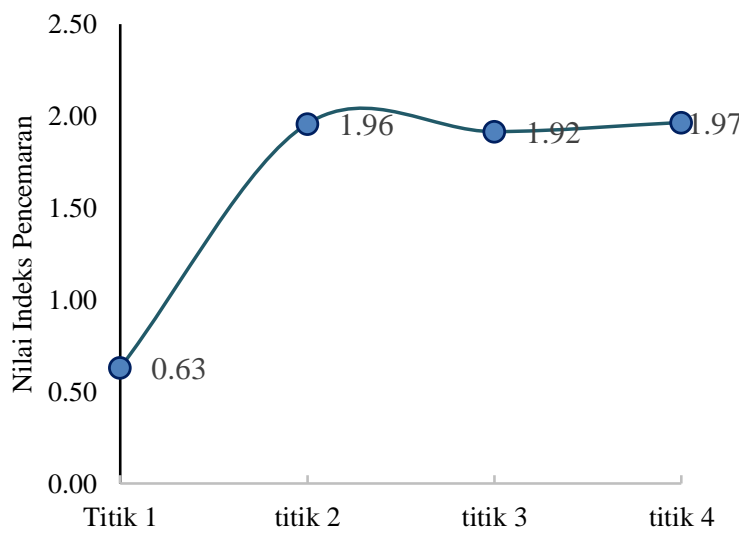

Gambar 2. Status Mutu Air Sungai Batang Asam

\section{Kesimpulan}

Berdasarkan hasil penelitian dan analisisyang dilakukan dapat disimpulkan sebagai berikut : 
1. Hasil analisis Kualitas Air Sungai Batang Asam yang diuji di Laboratorium BLHD Provinsi Jambi menunjukkan bahwa rata-rata dari 4 (empat) lokasi yang diuji adalah parameter $\mathrm{pH}$ 6,8, parameter TDS $79,5 \mathrm{mg} / \mathrm{l}$, parameter TSS $15,25 \mathrm{mg} / \mathrm{l}$, parameter DO $3,025 \mathrm{mg} / \mathrm{l}$, parameter BOD $2,935 \mathrm{mg} / \mathrm{l}$, parameter COD $14,5 \mathrm{mg} / \mathrm{l}$, Fe $0,645 \mathrm{mg} / \mathrm{l}$ serta parameter minyak dan lemak $1 \mathrm{Mg} / \mathrm{l}$. masih memenuhi baku mutu kualitas air kelas II. (PP No. 82 Tahun 2001).

2. Hasil analisis perhitungan dan penentuan status mutu air Sungai Batang Asam menggunakan Metode Indeks Pencemaran (IP) menunjukkankategori tercemar ringan karena nilai indeks pencemaran 1.0 $\leq \mathrm{IP} \leq 5.0$ yaitu 1,96 .

\section{Ucapan Terima Kasih}

Pada penelitian ini Penulis mengucapkan terima kasih kepada mahasiswa Program Studi Teknik Lingkungan dan Civitas Akademik Fakultas Teknik Universitas Batanghari serta masyarakat di sekitar Sungai Batang Asam Kabupaten Tanjung Jabung Barat Provinsi Jambi

\section{Daftar Pustaka}

Alaerts, G and Santika. (1984). Metoda Penelitian Air. Surabaya: Penerbit Usaha Nasional.

Asdak, C. 2010. Hidrologi dan Pengelolaan Daerah Aliran Sungai. Gajahmada University Press. Yogyakarta

Chandra, B. (2005). Pengantar Kesehatan Lingkungan. Jakarta: Kedokteran EGC.

Priyambada,I.B., Oktiawan,W., Suprapto,R,P,E. (2008). Analisa Pengaruh Perbedaan Fungsi Tata Guna Lahan terhadap Beban Cemaran BOD Sungai (Studi Kasus Sungai Serayu Jawa Tengah). Jurnal Presipitasi. Vol. 5. No. 2. pp 55-62.

Pemerintah Republik Indonesia. (2001). Peraturan Pemerintah Nomor 82 Tahun 2001 tentang Pengelolaan Kualitas Air dan Pengendalian Pencemaran Air. Jakarta

Pemerintah Republik Indonesia, (2011). Peraturan Pemerintah Nomor 38 Tahun 2011 tentang Sungai. Jakarta

Menteri Lingkungan Hidup Republik Indonesia. (2003). Keputusan Menteri Negara lingkungan Hidup Nomor 115 Tahun 2003 tentang Pedoman Penentuan Status Mutu Air.

Wardhana, Wisnu. (2004). Dampak Pencemaran Lingkungan. Yogyakarta: Penerbit ANDI. 